\title{
Ground-Motion Observations at Hotel Montana during the M 7.02010 Haiti Earthquake: Topography or Soil Amplification?
}

\author{
by D. Assimaki and S. Jeong
}

\begin{abstract}
Unusually severe structural damage was reported during the 2010 M 7.0 Haiti earthquake in the vicinity of Hotel Montana, located on top of a ridge in the district of Pétionville. Prompted by the observations, U.S. Geological Survey seismic stations were deployed, and aftershock recordings indicated ground-motion amplification on the top of the hill compared to adjacent stations on reference site conditions. The presence of topographic relief has been shown to significantly aggravate the consequences of strong ground motion during past events, and topographic effects were brought forward to explain the observations. In this paper, we test the hypothesis of topographic amplification as the dominant factor that contributed to the damage concentration in the vicinity of Hotel Montana. We initially conduct numerical simulations of the ridge seismic response assuming elastic homogeneous site conditions, and show that numerical predictions of topographic amplification disagree with the field data both in amplitude and in frequency. Conversely, while 1D ground-response analyses for the site conditions at the hilltop predict amplification in the same frequency range as the field data, they significantly underestimate the recorded amplitude. We then conduct numerical simulations of the foothill ridge response to seismic motion while accounting for soil layering, and qualitatively demonstrate that the recorded amplification is most likely attributed to coupled site-topographic amplification effects, namely to seismic waves trapped in the soft soil layers of the near surface, amplified as a consequence of reverberations, and further modified due to diffraction and scattering upon incidence on the irregular ground surface. Parametric investigations of the topography-soil amplification coupling effects are then conducted, and our results show that when accounting for a hypothetical soil-bedrock interface at $100 \mathrm{~m}$ depth, predictions are in excellent agreement with the observed motion.
\end{abstract}

\section{Introduction}

Topographic effects are associated with the presence of strong topographic relief (hills, ridges, canyons, cliffs, and slopes), complicated subsurface geometries (sedimentary basins, alluvial valleys), and geological lateral discontinuities (e.g., ancient faults, debris zones). These features have been shown to significantly affect the intensity, frequency content, and duration of ground shaking during earthquakes. Examples of topographic amplification of seismic ground motion are the peak ground acceleration $(\mathrm{PGA})=1.82 \mathrm{~g}$ recording by the hilltop Tarzana station during the 1994 Northridge earthquake (Bouchon and Barker, 1996), the Pacoima Dam (PGA = $1.12 \mathrm{~g}$ ) recording during the 1971 San Fernando earthquake, the recent extraordinary ground motion $(\mathrm{PGA}=2.74 \mathrm{~g})$ recorded at K-Net station MYG004 during the 2011 Tohoku earthquake on the crest of a $5 \mathrm{~m}$ high, steep man-made slope (Nagashima et al., 2012), and numerous others (see Geli et al., 1988; Bard, 1999; Assimaki, 2004).
Observational evidence from past earthquakes indicates that damage concentration occurs where steep slopes or complicated topography is present; buildings located on the tops of hills, ridges, and canyons have been shown to suffer more intense damage than those located at the base. There is also strong recorded evidence that surface topography affects the amplitude and frequency content of the ground motions. Reviews of such instrumental studies and their comparison to theoretical results can be found in Geli et al. (1988), Faccioli (1991), Finn (1991), and Bard (1999). Among others, a case study on the response of a steep site in the Southern Alps revealed a crest-to-base spectral ratio of 20 (Nechtschein et al., 1995). In another case study, records obtained on a small ridge revealed that their spectral ratio to recorded motions at a nearby station on flat ground were only a function of topography and site conditions and were nearly independent of the azimuth, distance, and size of the seismic events (Tucker et al., 1984). By contrast, topographic effects on 3D features were 
shown to be strongly dependent on source-station azimuth in studies conducted by Paolucci et al. (1999) and Maufroy et al. (2012), highlighting the complexity and numerous associated parameters involved in evaluating and predicting the topographic amplification of seismic motion.

The problem of scattering and diffraction of seismic waves by topographic irregularities has been studied by many researchers (e.g., Boore, 1972; Bouchon, 1973; Smith, 1975; Bard, 1982; Sanchez-Sesma et al., 1982; Tucker et al., 1984) who studied topographic effects using numerical techniques such as finite differences, finite elements, boundary elements, and discrete-wavenumber methods. A limited number of examples, which involve more complex simulations such as numerical models with soil layering and/or 3D effects, can be found in Zhenpeng et al. (1980), Sanchez-Sesma (1983), Bard and Tucker (1985), Geli et al. (1988), Bouchon et al. (1996), Ashford et al. (1997), and Paolucci et al. (1999). A comprehensive review of such analyses is given in a study by Assimaki (2004). In a comparative study of observations and predictions of topographic effects, Geli et al. (1988) showed that topographic amplification ratios typically range from 2 to 10 , whereas events have also been recorded with spectral amplifications on the order of 20 or more. Later, Bard (1999) summarized the findings by Geli et al. (1988) as follows:

1. There exists a qualitative agreement between theory and observations on ground-motion amplification at ridges and mountain tops, and de-amplification at the base of hills.

2. The observed or computed amplification is first-order related to the sharpness of the topography: the steeper the average slope, the higher the peak amplification.

3. Topographic effects are frequency-dependent; the stronger effects correspond to wavelengths comparable to the horizontal dimension of the topographic feature.

Topographic effects are not accounted for in design guidelines, attenuation relations, or hazard maps in the United States, despite the documented evidence on the role of topography in elevating seismic risk. Even further, analytical solutions and numerical methods available for site-specific problems significantly underpredict the observed amplifications, a discrepancy partially attributed by Geli et al. (1988) to simplified assumptions such as homogeneous half-space, elastic material behavior and monochromatic or narrowband incident pulses instead of broadband ground motions. Two exceptions are: (1) the European Seismic Code EC8 (2000), which proposes a correction factor for both cliff- and ridgetype topographies as a function of the slope height and inclination; and (2) the 1995 French Seismic Code Association Francaise de Génie ParaSismique (1995), which proposes a similar aggravation factor to account for 2D amplification on cliff-type topographies as a function of the cliff height and the slope inclination. Case studies, however, such as Tarzana Hill in Los Angeles (Bouchon and Barker, 1996) demonstrate that extremely high acceleration levels $(1.78 g$ ) may be associated with topographic features of small height $(H=18 \mathrm{~m})$ and low slope angle $\left(i=10^{\circ}\right)$, suggesting that there exist additional factors that control topographic amplification of seismic motion and should be investigated, if not explicitly accounted for as part of design recommendations.

In this paper, we analyze a case study of topographic effects from the catastrophic 2010 M 7.0 Haiti earthquake, during which the severe damage observations and aftershock-recorded amplification in the vicinity of Hotel Montana, located along a foothill ridge in northern Pétionville, brought topographic effects forward to explain the observations (Hough et al., 2011). To test this hypothesis, we conduct site-specific numerical simulations for the convex ground-surface geometry and soil profile at Hotel Montana comprising 1D site-response analyses, 2D analyses of seismic response of the ridge on a homogeneous elastic halfspace, and combined analyses of the layered soil profile with irregular surface geometry. We qualitatively demonstrate that the observed amplification is most likely attributed to coupling between soil layering and topographic amplification, heretofore referred to as soil-topography coupling effects. These effects differ from the superposition of $1 \mathrm{D}$ ground response and ray focusing alone, and arise from seismic waves trapped in the near-surface soil layers, amplified or deamplified as a consequence of soil-bedrock impedance and nonlinear response, and further modified due to scattering, refraction, mode conversion, and interference caused by the nonhorizontal ground surface.

We finally conduct a parametric investigation of the role of surface soil stiffness, soil thickness, and soil-bedrock impedance on the intensity of soil-topography coupling amplification, and show that when accounting for a soilbedrock interface at approximately $100 \mathrm{~m}$ depth, predictions are in excellent agreement with the observed motions. Our study highlights the complexity of the seismic wavefield in the near surface of layered soils with irregular surface geometry, and illustrates that the predicted levels of seismic groundmotion amplification in the vicinity of topographic features can be significantly improved when soil layering and ground-surface topography are simultaneously accounted for in numerical simulations. Similar conclusions have been drawn by previous studies such as Paolucci et al. (1999) for strong-motion observations obtained on an instrumented hill at Matsuzaki, Japan, and Graizer (2009) who revisited the case of Tarzana Hill and explained the extremely high acceleration levels as the result of soil amplification coupled to topographic effects.

\section{Macroseismic Observations and Aftershock Recordings}

The city of Port-au-Prince suffered widespread damage during the M 7.0 Haiti earthquake of 12 January 2010, with an officially announced death toll of 230,000 (Everhard et al., 2010), 97,294 residential structures destroyed, and 188,383 damaged beyond repair; the catastrophic consequences of the event were attributed to the proximity of epicenter and the 
poor construction quality of the residential structures. Site effects played a key role in the damage distribution (Geoengineering Extreme Events Reconnaissance, GEER, 2010), manifesting both as sediment-induced amplification and as ray focusing at convex features of the strong topographic relief. In this paper, we focus on the case study of Hotel Montana, which was located along a foothill ridge in northern Pétionville and suffered extensive damage during the mainshock along with a number of adjacent residential structures. Because of the ground-surface geometry at the site, the localized damage pattern was initially attributed to topographic effects (Hough et al., 2011).

Hough et al. (2011) deployed eight portable K2 seismometers equipped with force-balance accelerometers and, at two stations, velocity transducers to explore the damage distribution within Port-au-Prince. Two of these instruments were deployed in late January 2010, whereas the remaining six were deployed in early March. The location of the instruments is shown in Figure 1a, which also highlights the stations of interest in this study: station HHMT that was installed on the foothill ridge adjacent to Hotel Montana on medium-stiff site conditions (NEHRP Class C) with $V_{S 30}=$ $626 \mathrm{~m} / \mathrm{s}$, and station HCEA that was installed on competent (NEHRP Class B) site conditions with $V_{S 30}=1014 \mathrm{~m} / \mathrm{s}$ and was thus used as a reference station (Cox et al., 2011).

A number of weak motions associated with a series of M 3-4 aftershocks were recorded cleanly across the array with good signal-to-noise ratios. We here present analysis of the largest aftershocks, namely six events with magnitudes between 3.6 and 4.4 listed in Table 1 (see Hough et al., 2011).
Table 1

Aftershock Recordings by Hough et al. (2011) at HHMT and HCEA, for which Amplification was Observed in the Vicinity of $7 \mathrm{~Hz}$

\begin{tabular}{lcccc}
\hline & Month & Day & UTC & Magnitude \\
\hline Event 1 & 03 & 21 & $02: 44: 28$ & 3.7 \\
Event 2 & 03 & 28 & $07: 16: 17$ & 4.2 \\
Event 3 & 03 & 28 & $07: 16: 17$ & 4.2 \\
Event 4 & 05 & 03 & $05: 38: 48$ & 4.0 \\
Event 5 & 05 & 03 & $19: 21: 24$ & 4.4 \\
Event 6 & 05 & 07 & $21: 30: 04$ & 3.6 \\
\hline
\end{tabular}

Without processing, waveforms recorded at HHMT revealed significant amplification relative to the reference station HCEA in the frequency range (6-8) $\mathrm{Hz}$ as shown in Figure 2. It should be noted here that the widely scattered broadband amplification observed in the entire (1-8) $\mathrm{Hz}$ frequency range indicates the spectral ratio amplitude dependency on the source-receiver azimuth (see Fig. 3), and in turn elicits 3D amplification effects from the interaction between surface topography and subsurface features and irregular soil layering. Recent instrumental and analytical studies on the effects of source azimuth and mechanism on topographic amplification on 3D features can be found in Paolucci et al. (1999), Lee et al. (2009), and Maufroy et al. (2012). The lack of deeper crustal velocities, however, constrains our numerical models in the top $100 \mathrm{~m}$ of the profile, within which we adopt the engineering amplification paradigm of vertically propagating $S V$ waves. Paolucci et al. (1999) showed that simplified 2D models of complex topographic features with (a)

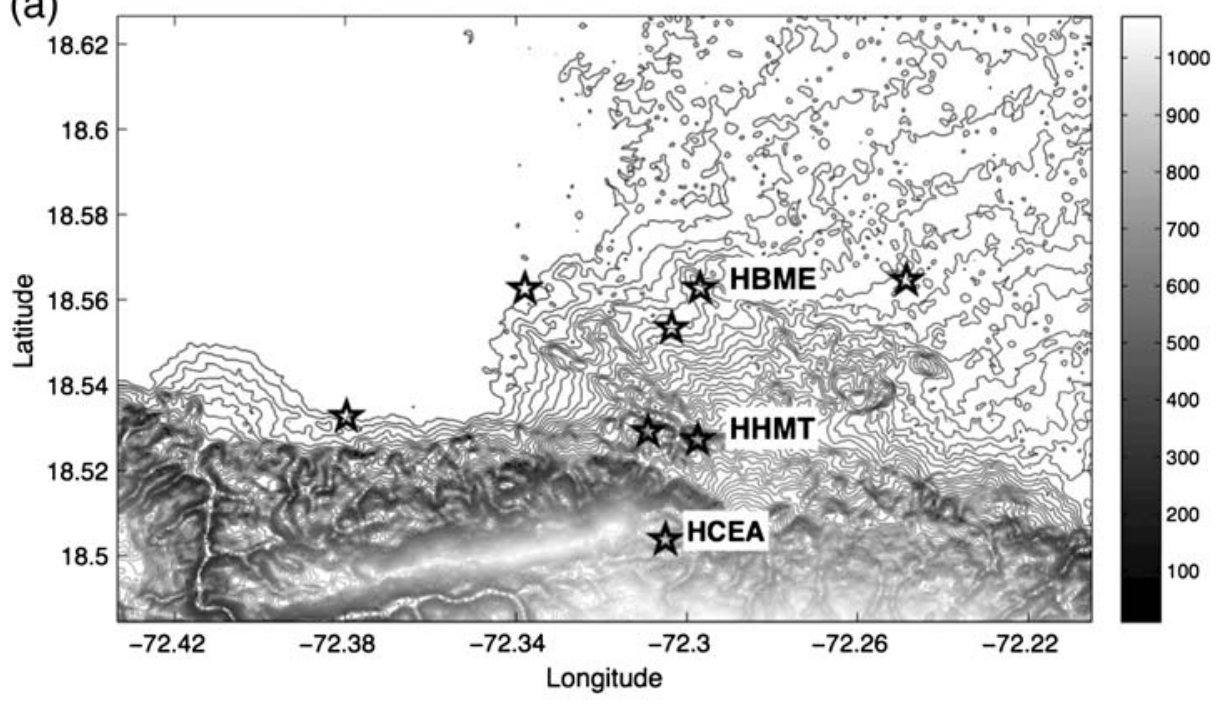

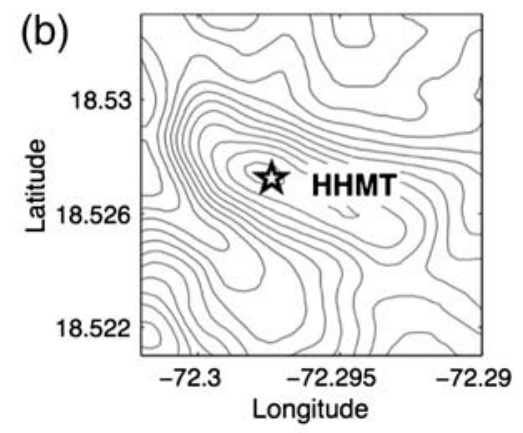

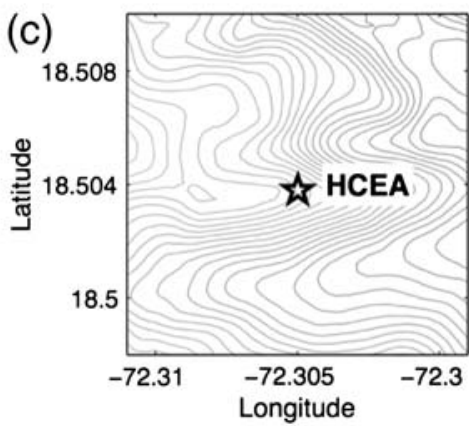

Figure 1. (a) Contour map and instrumentation (stars, stations) at Pétionville district: (b) Station HHMT is located adjacent to Hotel Montana atop a foothill ridge and (c) station HCEA is located on competent rock and was used as reference by Hough et al. (2011). 


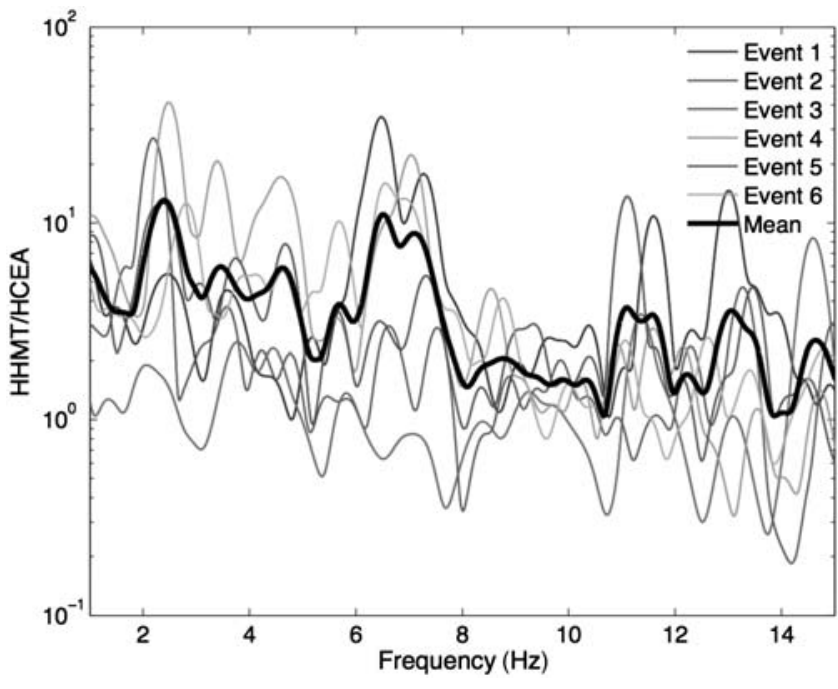

Figure 2. Spectral amplification of aftershock recordings at HHMT relative to HCEA in the vicinity of $7 \mathrm{~Hz}$, attributed to topographic amplification (modified from Hough et al., 2011).

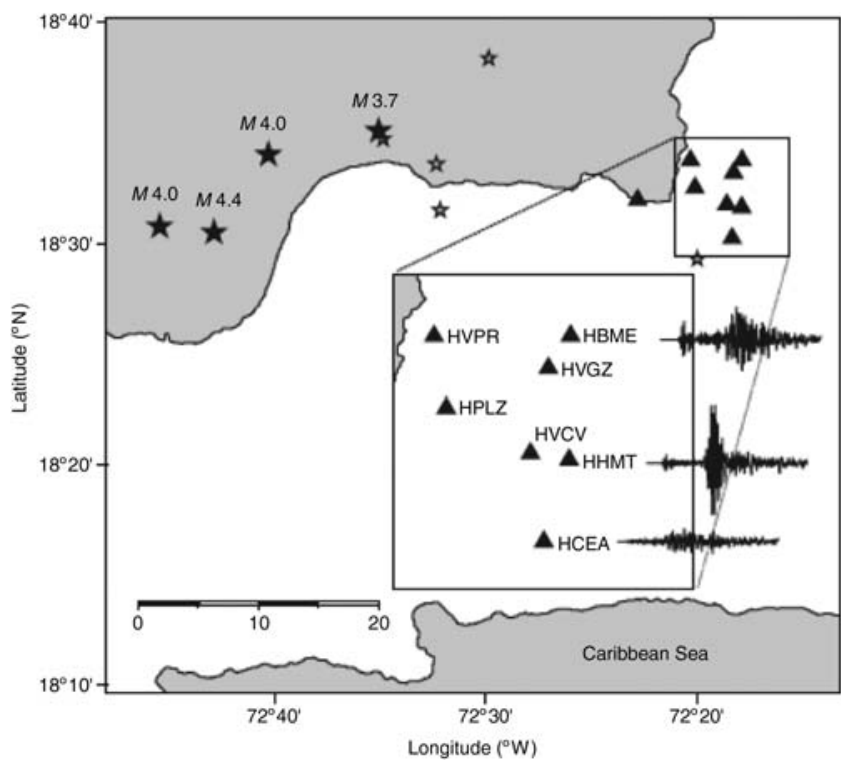

Figure 3. Map showing location of stations within Port-auPrince and sample recorded waveforms. Black stars, location of several of the moderate aftershocks and gray stars, smaller events recorded by black triangles, K2 stations; seismograms are the north-south component of ground motion for the 3.7 aftershock on 21 March 2010 recorded at HCEA, HBME, and HHMT (peak-to-peak PGA values $0.42,0.95$, and $1.68 \% \mathrm{~g}$, respectively; from Hough et al., 2011).

nonhomogeneous soil layering can yield valuable insight into the complex nature of site effects. Results presented in this paper should therefore be interpreted in the light of a simplified model partially explaining the recorded evidence to the extent that the latter is attributed to near-surface soil amplification and 2D topographic effects.

The ground-surface topography at HHMT in conjunction with the localized damage pattern and the relatively uniform, albeit poor, structural quality in Pétionville, suggested ray focusing in convex features as the most likely phenomenon explaining the macroseismic observations. Note that the theoretical prediction of ground-motion aggravation at HHMT using the infinite-wedge model proposed by SanchezSesma (1990) for a simplified geometry of the foothill ridge (internal angle $135^{\circ}$ ) and $\mathrm{SH}$-wave incidence yields a topographic amplification factor of 2.7 in the frequency range $(0-7) \mathrm{Hz}$. The agreement between the theoretical predictions and ground-motion recordings further supported the assumption of topographic effects as the dominant factor in the observed damage concentration atop the ridge.

To investigate the source of observed amplification and associated structural damage in the vicinity of Hotel Montana, we here conduct site-specific numerical simulations for the geometry and soil profile at station HHMT using digital elevation maps (DEM) and multichannel analyses of surface waves (MASW) data collected at the sites by Cox et al. (2011), and compare our predictions with the recorded ground-motion amplification. We choose to conduct linear elastic numerical analyses based on the maximum strain induced in the near surface by the available aftershock (weak) ground motions. More specifically, we first present results of 1D site-response analyses at HHMT and HCEA, and illustrate the negligible site amplification of the latter (reference site conditions) and the pronounced $7 \mathrm{~Hz}$ first-mode amplification of the former. Successively, we conduct 2D analyses of the topographic profile at HHMT and HCEA assuming a homogeneous half-space, and show that the observed spectral amplification cannot be explained by topographic amplification alone. We finally combine the two models into realistic simulations of the foothill ridge seismic response, and complement the site-specific analyses by a series of parametric studies.

\section{D Site-Response Analysis}

Following the mainshock, GEER (2010) sponsored an earthquake reconnaissance effort in the broader area of Port-au-Prince, as part of which, Cox et al. (2011) evaluated MASW shear-wave velocity profiles at 36 sites. The soil profiles at the sites of interest are shown in Figure 4, whereas the corresponding linear elastic frequency-domain site response, evaluated by means of the Haskell-Thompson transfer matrix method, is shown in Figure 5. As can be readily seen, the soil-column response at station HHMT is characterized by pronounced first-mode amplification at $7 \mathrm{~Hz}$, in the same frequency range as the observed ground-motion amplification; the latter, however, was on the order of 10-20, approximately five times the predicted 1D soil amplification of amplitude $3-4$. On the other hand, the stiff site conditions at HCEA yield a relatively flat transfer function up to $10 \mathrm{~Hz}$, and render the site an excellent candidate for site amplification reference; the computed 1D soil response of the profile at the reference station is also shown in Figure 5. 


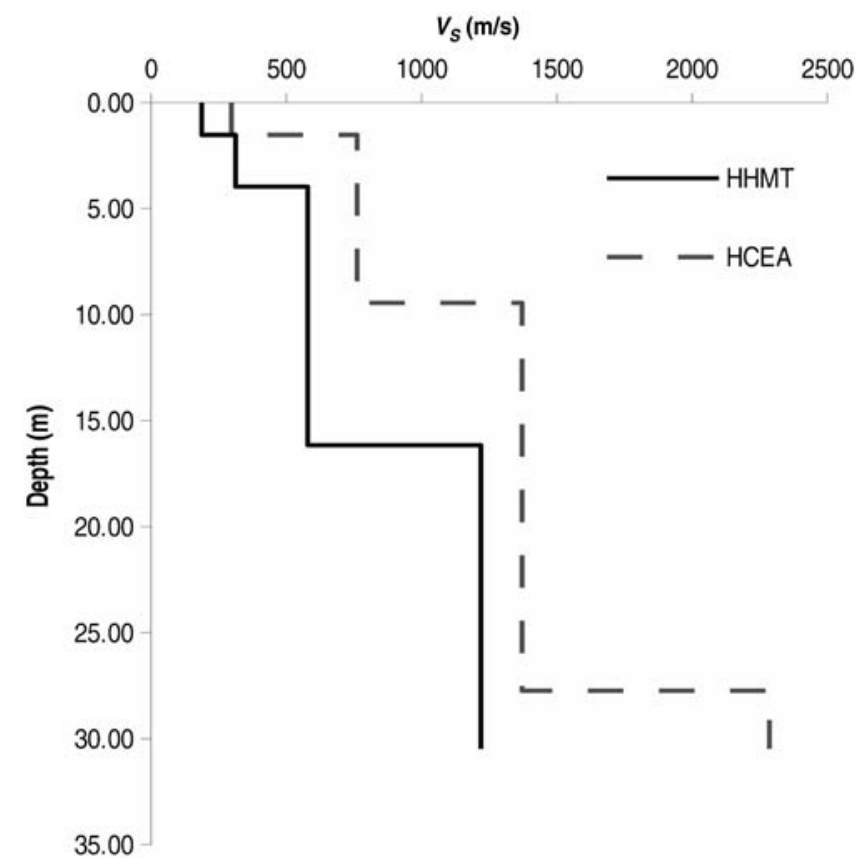

Figure 4. Shear-wave velocity in the top $30 \mathrm{~m}$ at stations HHMT and HCEA evaluated by means of multichannel analyses of surface waves (MASW).

\section{Site-Specific Simulations of Topographic Amplification}

We next investigate the effects of surface topography on the aggravation of seismic motion relative to flat ground conditions. The numerical models are shown in Figure 6 and the simulations are conducted by means of the finite-element computer code DYNAFLOW (Prévost, 1995). The far-field boundaries of the computational domain are located at adequate distance to approach 1D conditions and are thus constrained in the vertical direction, the ground motion is simulated as incident seismic pulse at the base of the models in the form of effective forces, and absorbing boundaries are implemented at the bottom of the model to represent the effects of reflected energy radiation toward the simulated half-space. Details on the simulations of $2 \mathrm{D}$ topographic amplification by means of finite elements can be found in Assimaki, Gazetas, and Kausel (2005) and Assimaki, Kausel, and Gazetas (2005). The dimensions of the topographic features at HHMT and HCEA are extracted from the DEM of the area shown in Figure 1 (A. Yong, personal comm., 2011).

\section{Homogeneous (Reference) Configuration}

We first study the ground-motion amplification arising from the irregular surface geometry alone by simulating the response of the features at the locations of stations HHMT and HCEA by means of linear elastic 2D analyses assuming homogeneous half-space soil conditions and vertical $S V$-wave incidence. The shear-wave velocity of the homogeneous half-space for both features is here set at $V_{S}=2286 \mathrm{~m} / \mathrm{s}$,

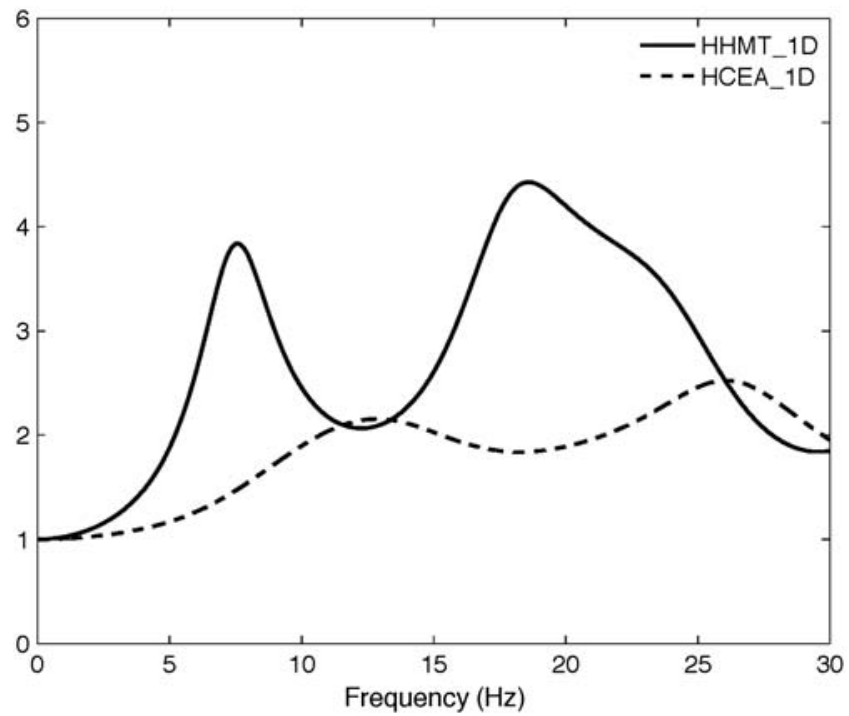

Figure 5. Haskell-Thompson linear elastic transfer function at the two sites, revealing the HCEA site relatively flat response in the frequency domain and the pronounced site amplification at HHMT in the vicinity of $7 \mathrm{~Hz}$.

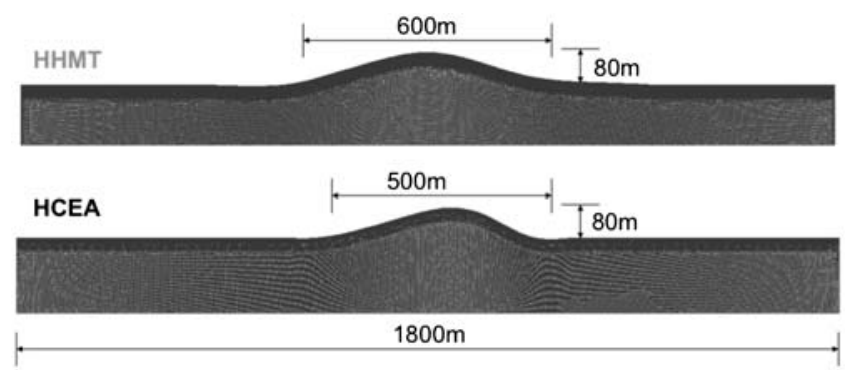

Figure 6. 2D finite-element models for the response analysis of topographic features, constructed on the basis of DEM data; station HCEA is installed on a ridge with dimensions comparable to HHMT.

which corresponds to the the bedrock velocity measured by MASW at the reference station HCEA. The features are subjected to an incident train of Ricker wavelets with central frequencies $0.5,2.5,5$, and $10 \mathrm{~Hz}$. The incident waveform and corresponding Fourier Amplitude Spectra (FAS) are shown in Figure 7, and results are shown in Figure 8. The Fourier amplitude spectral surface (FASS) at station HHMT subjected to a Ricker wavelet train is shown in Figure 8 depicting the frequency response of the feature as a function of space along the surface of the finite-element model in Figure 6. The cross section $\mathrm{AA}^{\prime}$ corresponds to the FAS of the ground-surface response at the vertex of the foothill ridge (i.e., approximately at the midpoint of the $600 \mathrm{~m}$ wide feature idealized in Fig. 6), adjacent to Hotel Montana.

It should be noted here that the ground-surface topography at stations HHMT and HCEA is very similar, which in turn implies that the frequency response of the homogeneous irregular topographic features is also expected to be 

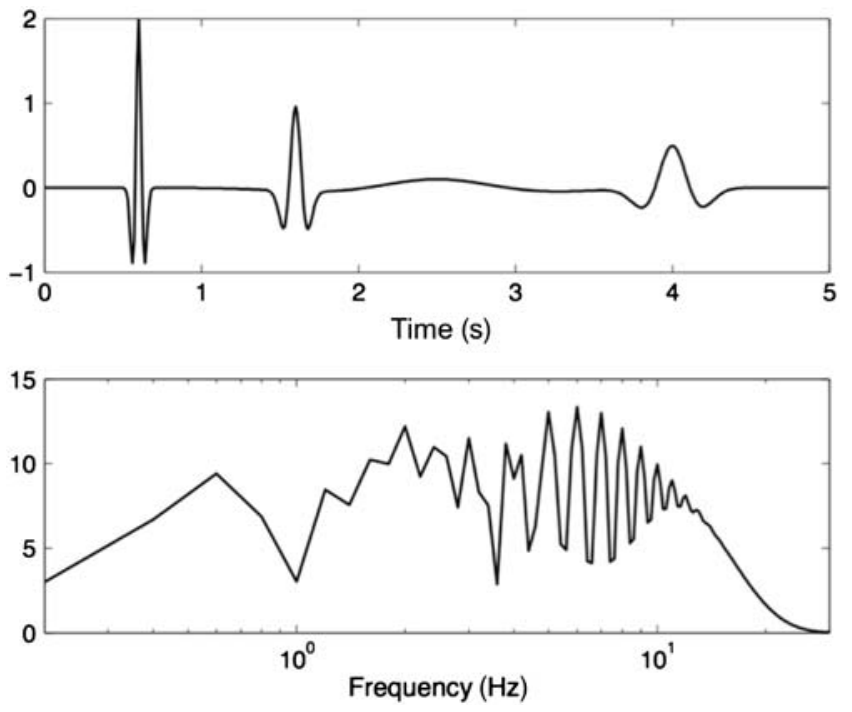

Figure 7. Input motions used in the simulations: A train of Ricker wavelets that shows flat distribution of energy over a wide band of frequencies for evaluating the frequency response of the ridge.

similar. Indeed, the FAS's on the vertices of the homogeneous features HHMT and HCEA are compared in Figure 8b, and one can clearly see that the frequency response of the two features is almost identical for frequencies in the vicinity of $7 \mathrm{~Hz}$, for which amplification was identified in the recorded ground motions. It should be also noted here that the 1D ground response at the reference station HCEA shown in Figure 5 is relatively flat in the frequency range of interest (6-8) Hz. Given that the geometry at stations HCEA and HHMT yields practically equal topographic amplification, and the soil profile at HCEA results in almost no soil amplification, we will assume for simplicity that the response of

(a)

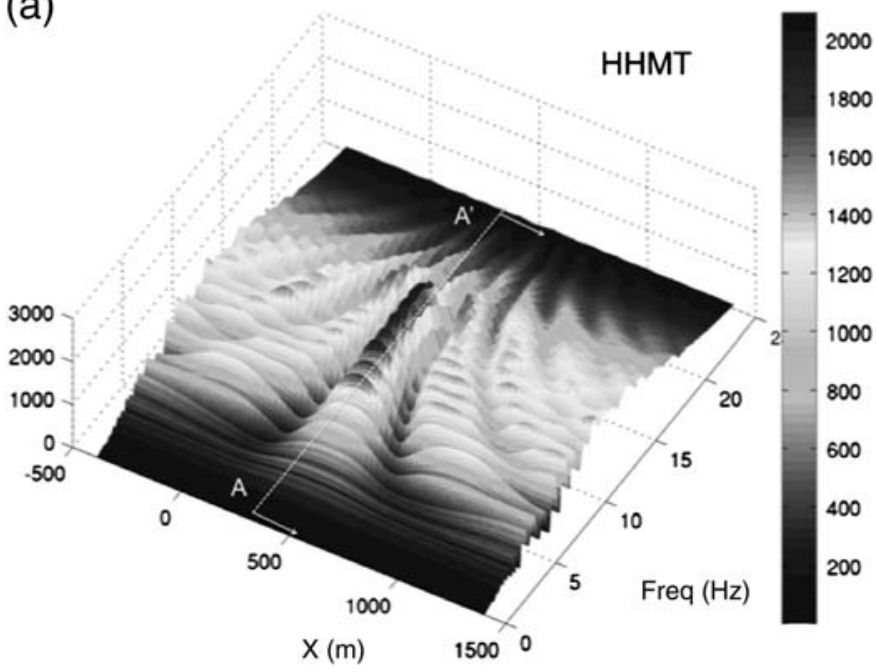

the HCEA reference feature is approximately equal to the response of the homogeneous HHMT feature, and use the latter in the parametric analyses of soil-topography coupling effects.

\section{Layered Configuration: Soil-Topography Coupling Effects}

Successively, we integrate the effects of stratigraphy by adding continuous soil layers on the surface of the half-space, computing the coupled response of layered feature HHMT with irregular ground-surface geometry, and comparing results with the homogeneous feature used to approximate the response of HCEA (denoted heretofore as reference configuration). Because of the lack of multiple spectral analysis of surface waves (SASW) measurements at the site of interest that would allow us to develop a spatially varying soil stratigraphy, we adopt the assumption of uniform thickness across the irregular topographic feature. A potentially more realistic approach would involve laterally varying soil thickness with the minimum located on the crest and the maximum in front of the toes. Preliminary analyses using this configuration, however, revealed focusing effects similar to basin-edge effects emerging in the vicinity of the toes that substantially complicated the scattered wavefield. In absence of additional geotechnical data to support a spatially varying soil profile (and the associated more complex wavefield), we chose to abort this model for the more simplified uniform-thickness soil presented later. This allows us to study the interaction between 2D topography and 1D layering, and build upon this simplified configuration future analyses that could include 3D effects and spatially varying soil formations among others.

A narrowband Ricker pulse with central frequency $7 \mathrm{~Hz}$ is selected as a vertically propagating incident wave, containing energy in the frequency range in which amplification was

(b)

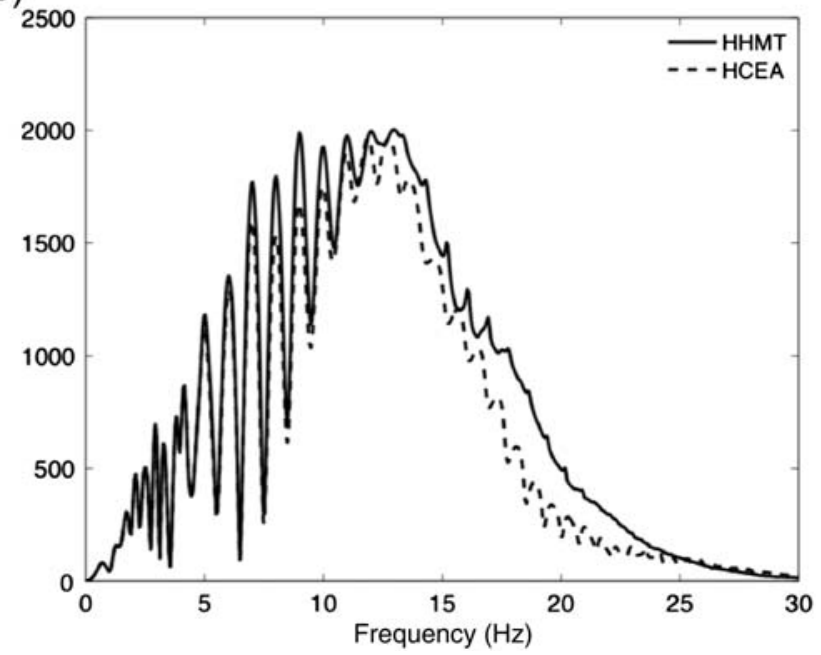

Figure 8. Fourier amplitude spectral surface (FASS) plot on the ground surface the topographic feature of HHMT assuming (a) homogeneous soil conditions, and (b) comparison of the vertex FAS of HHMT and HCEA. Note that the homogeneous response of the two features is shown to be almost identical in the frequency range of ground-motion recorded amplification. 
(a) 1500

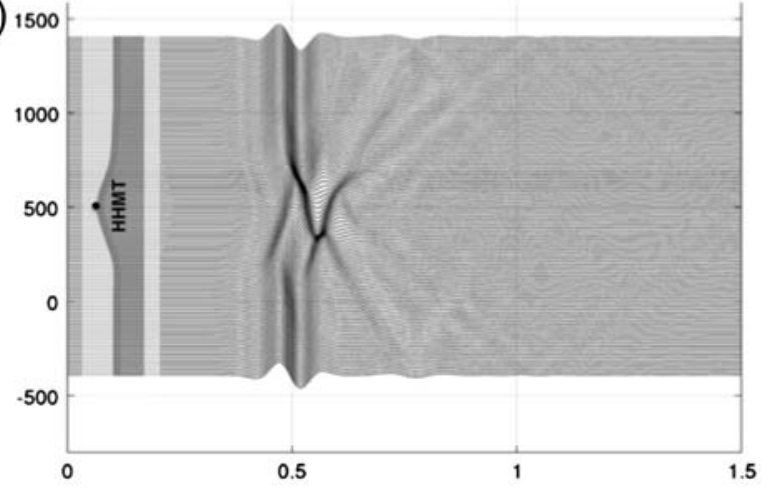

(c)

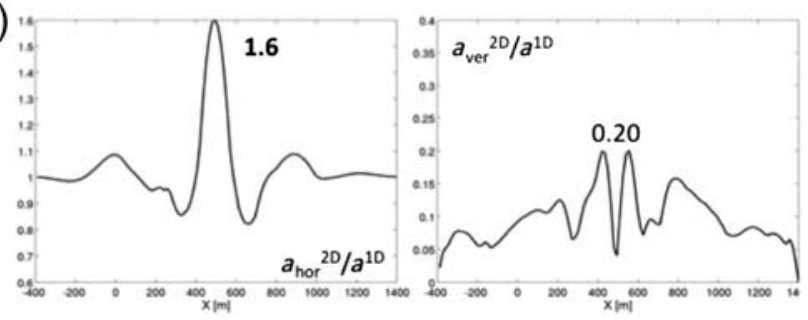

(b) 1500

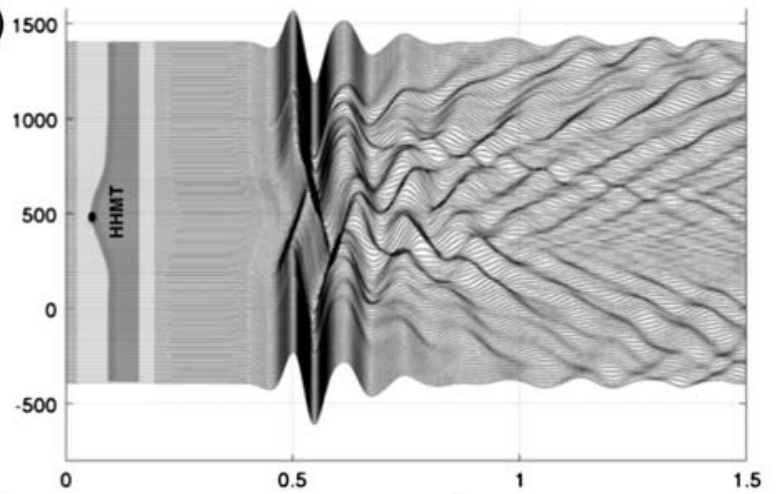

(d)
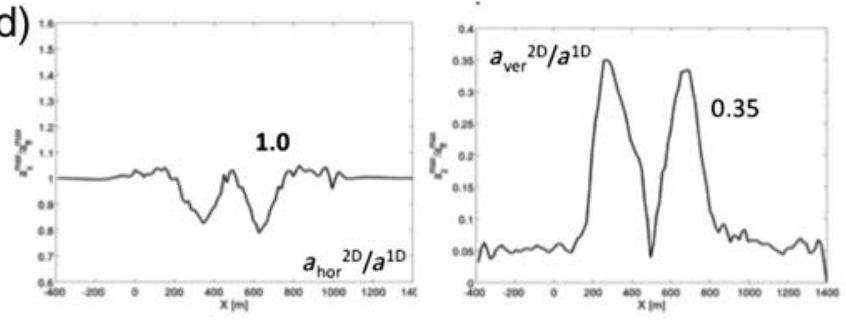

Figure 9. (a,b) Horizontal acceleration seismogram synthetics for $(a, c)$ the homogeneous ridge and $(b, d)$ the ridge with measured velocity profile, subjected to a Ricker wavelet with $f_{0}=7 \mathrm{~Hz}$ as input velocity pulse at the base of the model; (c,d) horizontal and vertical (parasitic) peak ground acceleration (PGA) along the surface of the two configurations, normalized by corresponding horizontal PGA in the far field (1D conditions).

observed in the field recordings. It should be noted here that for the reference configuration $\left(V_{S}=2286 \mathrm{~m} / \mathrm{s}\right)$, a pulse with frequency $7 \mathrm{~Hz}$ corresponds to wavelengths approximately equal to half the width of the topographic feature, and is in turn anticipated to give rise to topographic amplification (Bard, 1999).

Results are presented in Figure 9 as ground-surface seismogram synthetics on the reference configuration and layered feature (vertex HHMT corresponds to the location of Hotel Montana), and as PGA (horizontal and vertical) normalized by the corresponding value in the free field. The term free field is used to describe the response recorded by a station far enough from the irregular topographic feature where the ground-surface motion is free from the scattered and diffracted wavefield. With the assumption of a horizontally stratified soil, the free-field response is identical to the 1D site response described above. Seismogram synthetics of horizontal and vertical motion for the homogeneous and layered configurations are also compared in Figure 10 in which the frequency-dependent nature of soil and topographic amplification can be readily seen by qualitatively comparing the configuration response to three wavelets of different frequency content.

As expected, seismogram synthetics on the surface of the reference feature depict the constructive interference of direct incident and uphill-traveling surface waves at the vertex, which result in 60\% amplification of the incident horizontally polarized $S V$-wave amplitude, and vertical acceleration with amplitude $20 \%$ of the PGA in the free field. Counterintuitively, however, the ground-surface response of the layered feature (where topographic effects are coupled to site amplification) shows almost no amplification at the vertex relative to the free field. Instead, we observe approximately $20 \%$ deamplification along the slopes of the foothill ridge due to destructive interference between shear waves trapped and reverberating in the near surface, and surface waves traveling uphill. The complexity of the wavefield compared to the homogeneous case can be clearly seen in the seismogram synthetics, in which the reverberating shear waves repeatedly produce surface waves upon incidence on the surface discontinuities while gradually attenuating as a result of refraction and energy radiation toward the half-space. By contrast, the vertical component on the ground surface is here more pronounced than in the reference configuration shown in Figure 10a,c, with peak amplitude 35\% of the farfield PGA in the vicinity of the vertex. Note that the incident ground motion comprises purely vertically propagating $S V$ waves (horizontally polarized particle motion), whereas the ground-surface response comprises both horizontal and vertical motion components; the latter corresponds to the surfacewave components converted from scattered and diffracted body waves upon incidence on the nonflat ground surface, and is for this reason termed parasitic vertical acceleration.

Results described previously indicate that coupling between topographic effects and soil amplification gives rise to complex phenomena that cannot be captured via superposition. More specifically, incident seismic waves in the near surface of irregular topographic features are trapped in the softer soil layers, and further amplified as a result of the impedance contrast, while simultaneously scattered and 

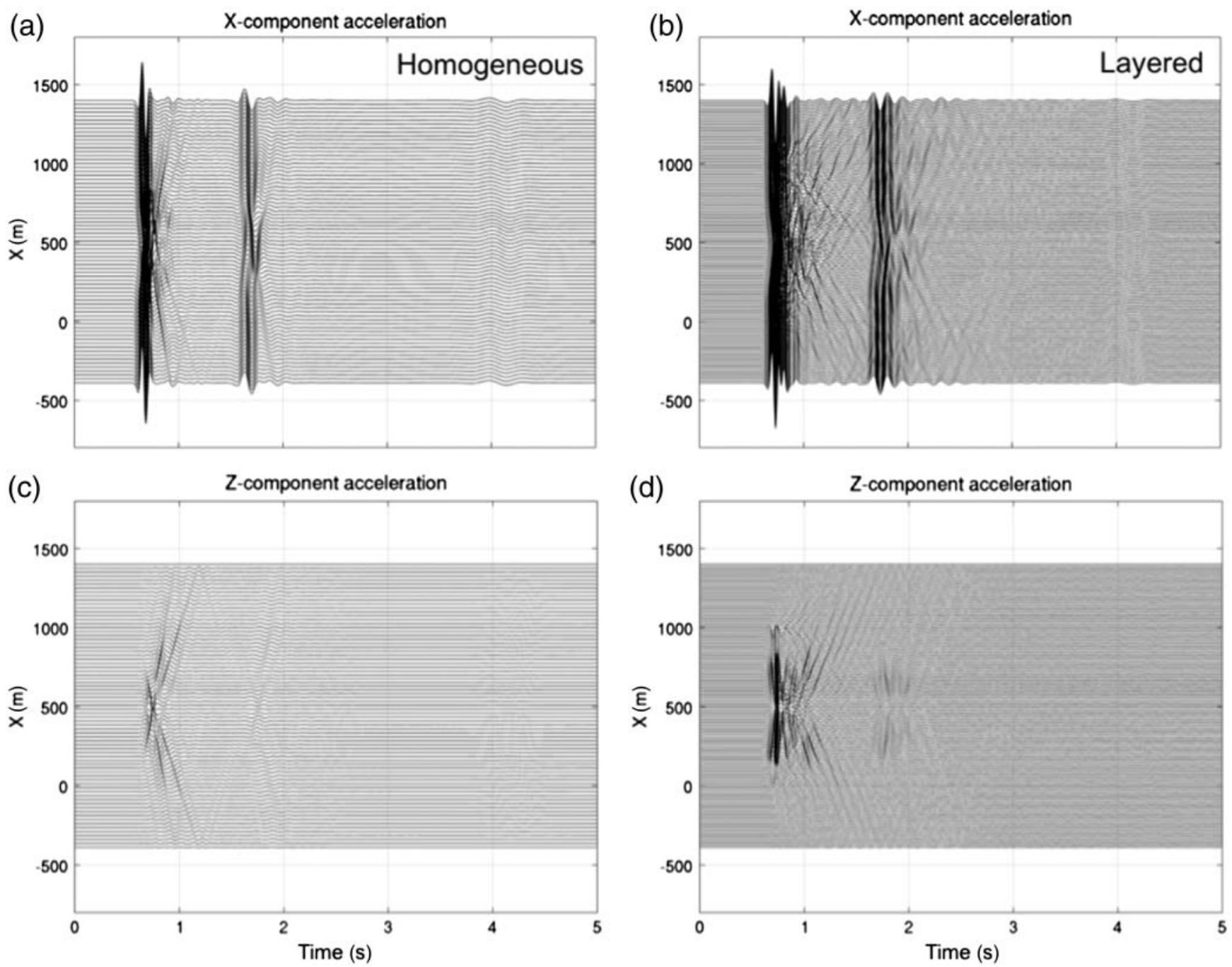

Figure 10. (a,b) Horizontal and (c,d) vertical acceleration synthetics for the (a,c) homogeneous and (b,d) layered configurations subjected to incoming vertically propagating train of Ricker wavelets, illustrating the frequency-dependent nature of soil and topographic amplification and their interaction at the hilltop.

refracted due to the irregular surface geometry. To illustrate this concept, Figure 11 compares the 1D site response at HHMT shown in Figure 5 to the spectral acceleration ratio of the layered configuration vertex (HHMT) to the reference configuration vertex (approximating the response of station HCEA). As can be seen, the response of the stratified feature normalized by the response of the homogeneous feature is not equal to the 1D soil amplification transfer function. Instead, coupling effects give rise to a topography-modified site response, which differs from the free-field 1D response by a frequency-dependent factor $\alpha(\omega)$ as follows:

$$
\frac{U_{\text {layered }}^{2 \mathrm{D}}}{U_{\text {homogeneous }}^{2 \mathrm{D}}} \approx \frac{U_{\mathrm{Rec}}^{\mathrm{HHMT}}}{U_{\mathrm{Rec}}^{\mathrm{HCEA}}}=U_{\text {layered }}^{1 \mathrm{D}} \cdot \alpha(\omega)
$$

The topographic amplification on each feature (layered and homogeneous) is also depicted by Figure 11a as the spectral ratio of predicted acceleration on the vertex (2D) to the acceleration in the free field (1D). For the homogeneous case, the amplification due to topography is very mild and extends over a wide range of frequencies, whereas for the layered case, amplification is observed only in the frequency range $3-5 \mathrm{~Hz}$, followed by deamplification in the vicinity of $7 \mathrm{~Hz}$. Similarly, comparing the 1D free-field response to the topography-modified site response at HHMT (Fig. 11b), we observe that the coupling effects reduce the site amplification potential of the near-surface stratigraphy at the profile's first mode in the vicinity of $7 \mathrm{~Hz}$, namely in the range for which amplification was observed in the recorded ground motions at Hotel Montana.

Successively, Figure 12 compares the predicted topography-modified site response at HHMT to the mean frequency ratio of the recorded ground motions shown in Figure 2, revealing qualitative agreement in the frequency range (5-8) Hz. For comparison, Figure 2 also depicts the ratio of predicted layered HHMT response to the predicted 


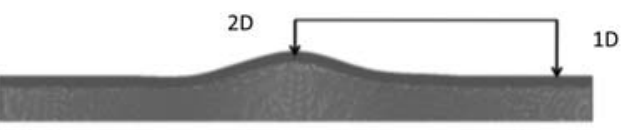

(a)

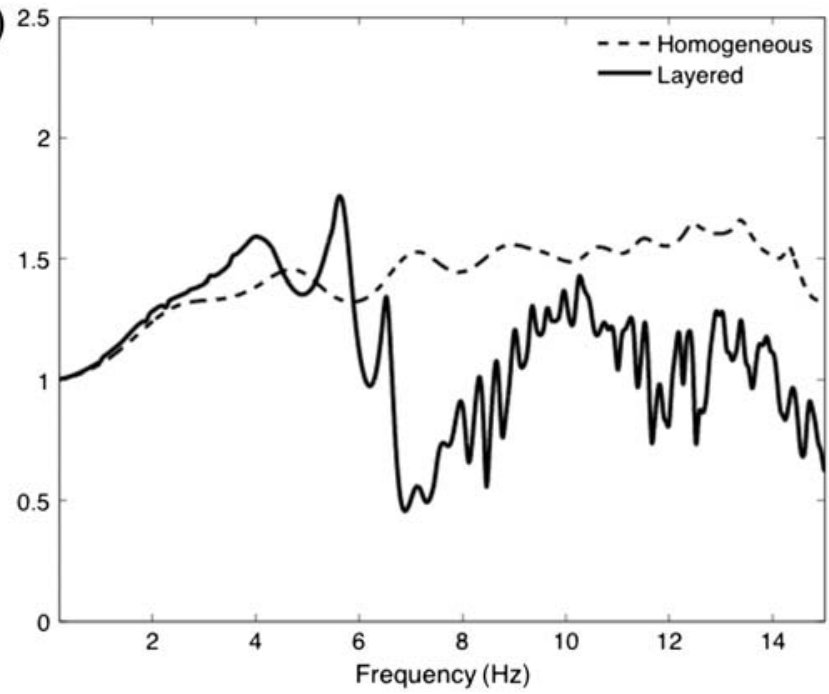

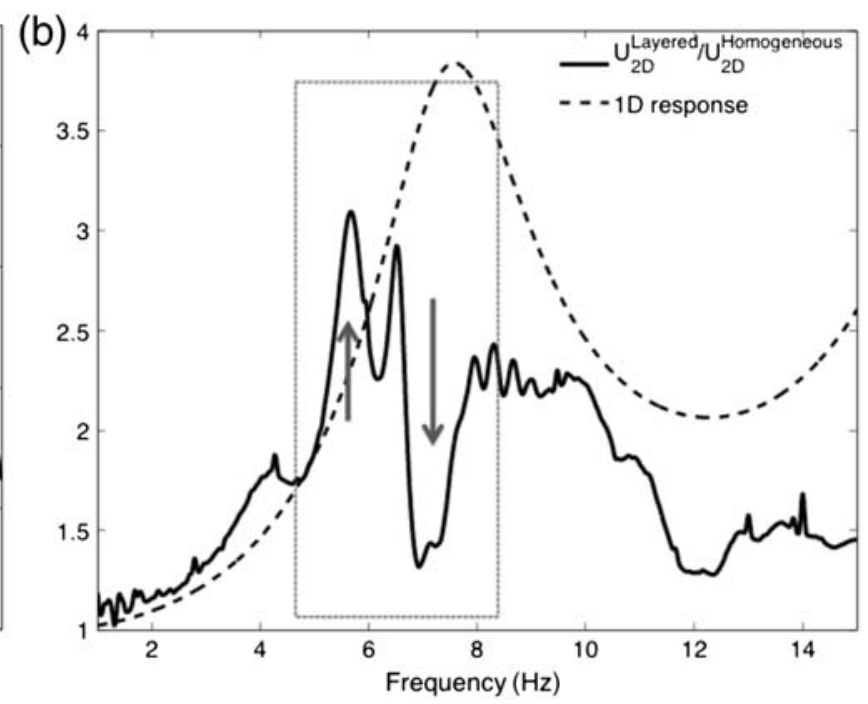

Figure 11. (a) Comparison of the frequency response functions of the ridge: dashed line, the response of homogeneous ridge and the continuous line, the response of the ridge with measured velocity structure; (b) frequency response of the ridge with measured velocity structure normalized by the response of homogeneous ridge (approximately equal to HCEA): frequency response of 1D soil column at HHMT is plotted in dashed line for comparison.

HCEA response, accounting for the 1D layered structure at both features (here approximated by the response of layered HHMT to homogeneous HHMT), and the 1D soil amplification transfer function at HHMT. Results illustrate that soil response is likely to have had the strongest contribution to the amplification recorded at Hotel Montana. Results also show that whereas topography-induced amplification alone could explain the structural damage severity at the station, coupled topography-soil effects do capture the frequency range of amplification. Quantitatively, however, numerical simulations and field observations show a clear discrepancy, differing in magnitude by a factor of three. In the ensuing section, we identify the parameters most likely controlling the magnitude of ground-motion amplification, and speculate the origin of the discrepancy between theory and observations.

\section{Parametric Study of Coupled Topography-Soil Amplification at HHMT}

In the preceding sections, we numerically simulated the ground-motion amplification published by Hough et al. (2011), who normalized the ground-surface recordings on a foothill ridge (station HHMT) with the recordings on a similarly shaped, 2D feature (station HCEA) with reference site conditions in accordance with the criteria by Steidl et al. (1996). We next showed that the observed amplification is most likely attributed to the altering of soil response by the irregular ground-surface geometry. We termed the complex interaction between soil and topographic amplification a soil-topography coupling effect, and qualitatively described

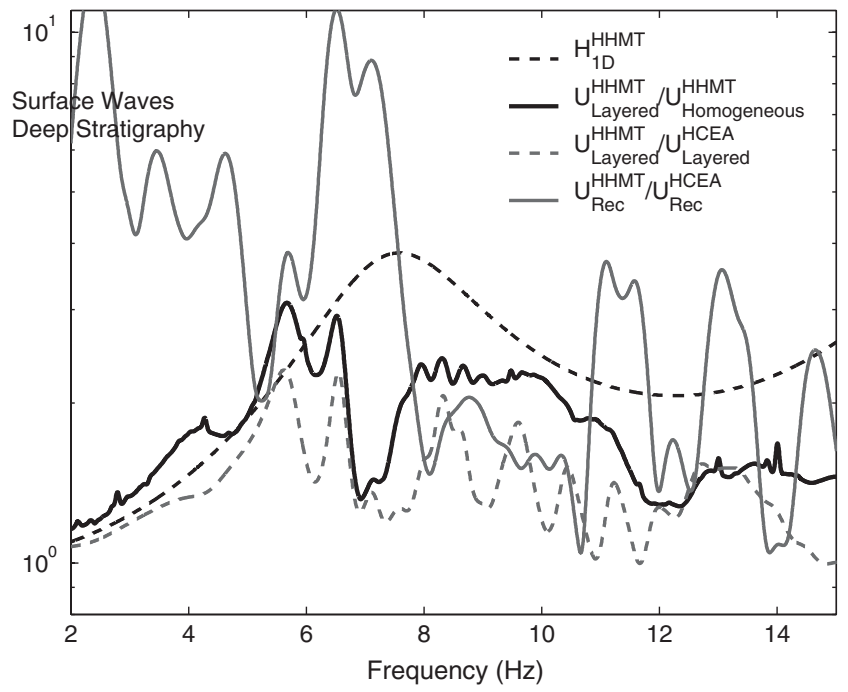

Figure 12. Spectral ratio of the recorded response at HHMT over HCEA, compared against the computed ratio of HHMT to HCEA, the ratio of layered HHMT to homogeneous HHMT, and the 1D response of the soil column at HHMT. Numerical simulations of the seismic response of layered topographic features capture the frequency range of recorded amplification, however, at a significantly, lower amplitude.

it as the trapping of seismic waves in the surficial soil layers, and the subsequent altering of their direction, amplitude, frequency, and duration due to scattering and refraction upon incidence on the irregular ground-surface geometry. However, our numerical results qualitatively agree with 


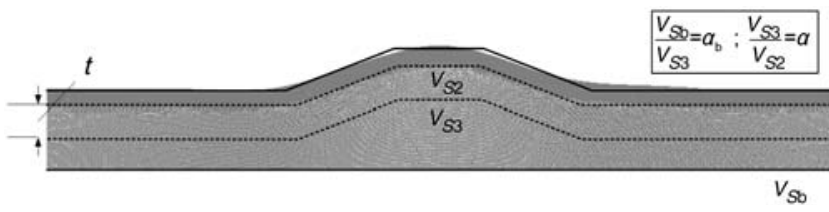

Figure 13. Idealized three-layer, dam-shaped configuration over homogeneous elastic half-space used in the parametric investigation of the factors that contribute to the discrepancy in amplification amplitude between observations and simulations.

the observed amplification in terms of frequency, they clearly deviate in terms of amplitude by a factor of almost three.

We here investigate this discrepancy by conducting a series of analyses to identify the parameters affecting the magnitude, frequency content, and spatial distribution of ground-motion amplification in the vicinity of Hotel Montana. More specifically, we investigate the role of the thickness of the surficial layers $(t)$, the impedance contrast between the soil layers $(\alpha)$, and the impedance contrast between the soil and underlying elastic bedrock half-space $\left(\alpha_{\mathrm{b}}\right)$. For the latter, we assume a hypothetical soil-half-space interface at $h=100 \mathrm{~m}$, a common geotechnical engineering assumption in which the half-space is referred to as engineering bedrock.

For the purpose of the parametric investigation, the geometry and stratigraphy of the HHMT ridge are simplified as shown in Figure 13. Figure 14 compares the FASS of the original and simplified homogeneous HHMT ridge, and Figure 15 compares the 2D-to-1D spectral ratio at the vertex of the original and simplified HHMT layered ridge, as well as the ground-surface horizontal and vertical PGA of the two, normalized by the corresponding site response in the free field. Results are found to be in excellent agreement in both the frequency and the spatial domains, which allows us to replace the original layered $2 \mathrm{D}$ feature with the simplified

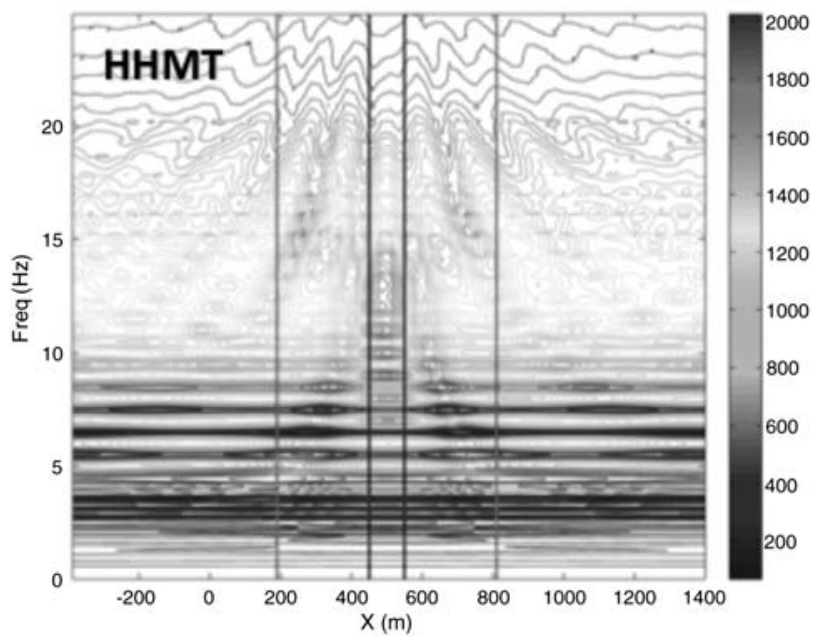

configuration in our parametric study with no significant loss of accuracy. Note that the soil profile of the original feature corresponds to the MASW inversion shown in Figure 4, whereas the latter is idealized by a three-layer formation overlying elastic half-space. The objective of this part of the paper is to identify the parameters that contribute to the observed amplification in the $6-8 \mathrm{~Hz}$ frequency range, and the parameters that give rise to the observed low frequency peaks in the frequency range $3-4 \mathrm{~Hz}$.

To minimize the number of parameters, we note the following:

1. The weighted average shear-wave velocity of the top three layers at HHMT (Fig. 4) is $443 \mathrm{~m} / \mathrm{s}$, and the quarter wavelength of a monocromatic pulse with frequency $7 \mathrm{~Hz}$ (at which amplification was observed by Hough et al. [2011]) is $\lambda / 4=15 \mathrm{~m}$, approximately equal to the cumulative thickness of these layers $(17 \mathrm{~m})$. We therefore conclude that the resonant frequency of the site in the vicinity of $7 \mathrm{~Hz}$ corresponds to the response of the top three layers for which the shear-wave velocity was measured via MASW by Cox et al. (2011), and we in turn fix the thickness and average velocity of the top three layers in our simplified configuration as $t_{1}=20 \mathrm{~m}$ and $V_{S 1}=500 \mathrm{~m} / \mathrm{s}$, respectively.

2. The amplification local maximum in the range of $3-4 \mathrm{~Hz}$ corresponds to a quarter wavelength of approximately $50 \mathrm{~m}$ for the weighted average of all four layers reported by Cox et al. (2011). Because the maximum depth of the site investigation was $30 \mathrm{~m}$, we select the thickness of the second idealized layer as a parameter of the study in the range $t_{2}=10-50 \mathrm{~m}$. We also select the impedance contrast between the second and third soil layers as a parameter that will control the amount of energy trapped above the interface, and that accordingly amplifies the ground motion via reverberations in the vicinity of

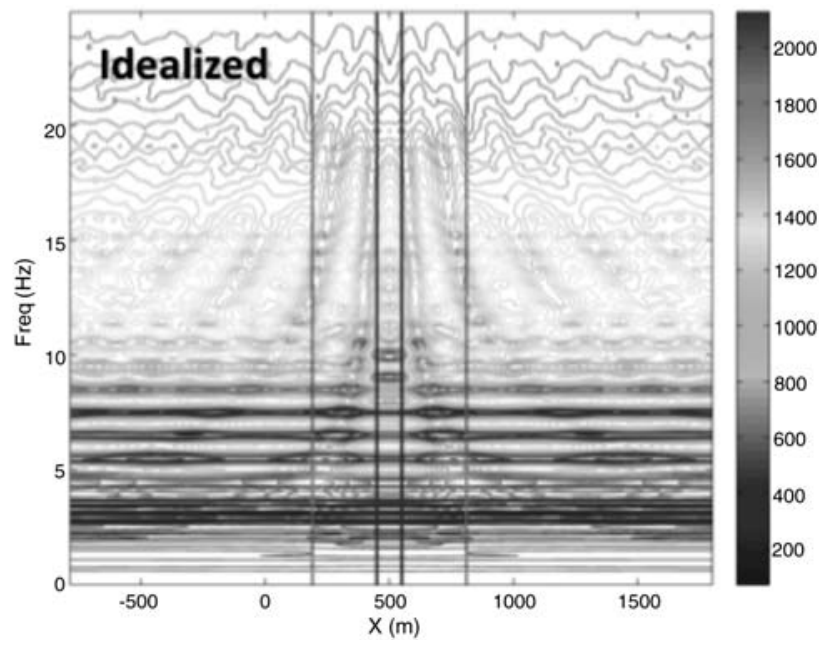

Figure 14. Comparison of the Fourier amplitude spectral surface (FASS) on the surface of the original and idealized HHMT ridge subjected to a vertically propagating train of Ricker wavelets. The idealized configuration response compares very well with the original feature response, and is thereafter used instead for the parametric analysis. 


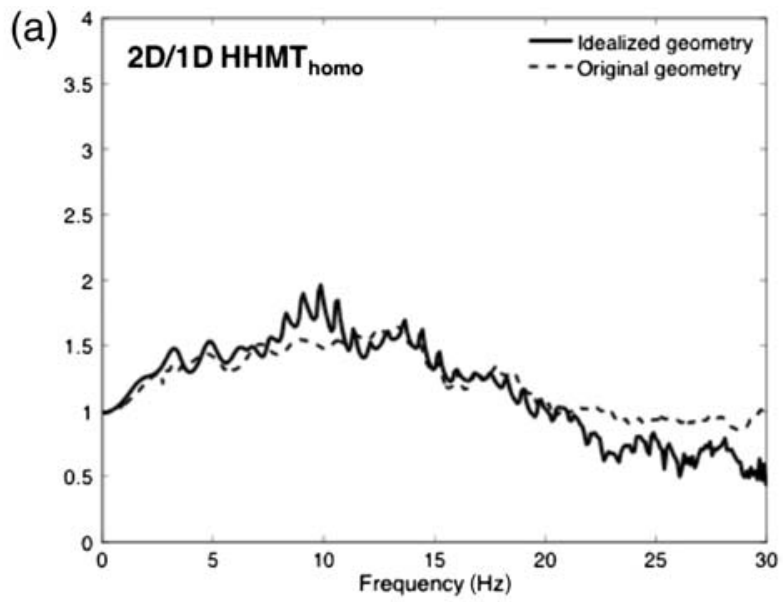

(b)

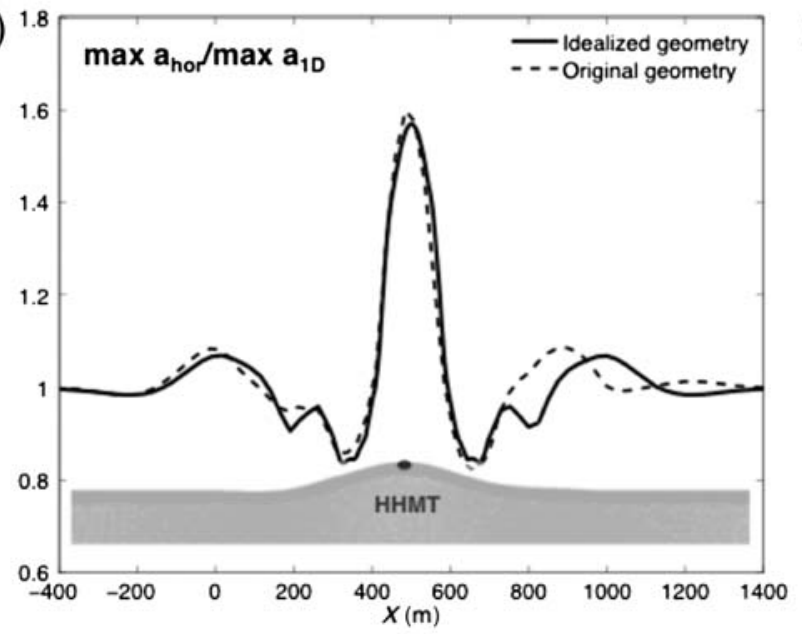

(c)

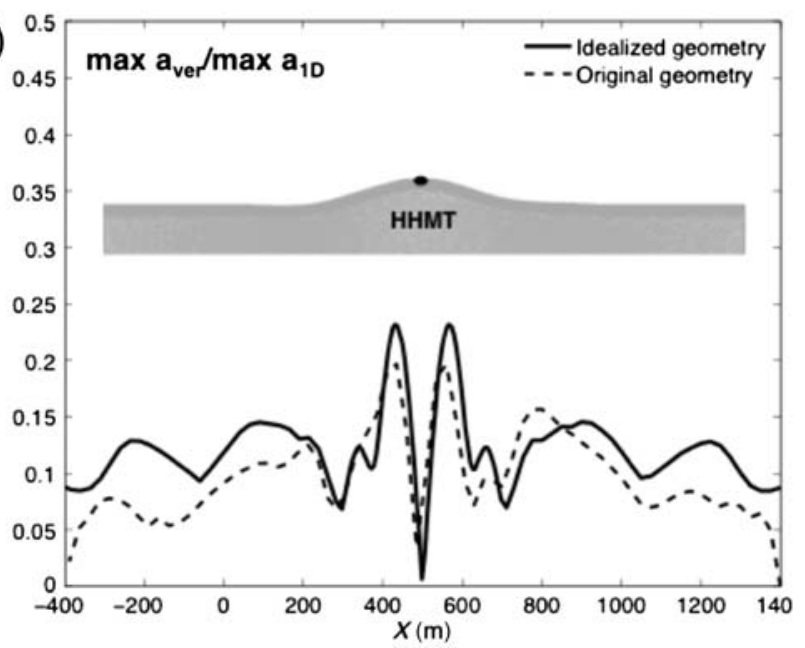

Figure 15. (a) Comparison of the frequency response at the midpoint of the original and idealized HHMT ridge normalized by the farfield (1D) response of the layered profile, showing the excellent agreement of the frequency response of the two features. Their response in terms of (b) horizontal and (c) vertical PGA along the surface, normalized by the horizontal far-field response (1D) is also compared and found to be in good agreement.

3-4 Hz. We denote this parameter $\alpha=\left(\rho_{3} V_{S 3}\right) /\left(\rho_{2} V_{S 2}\right)$, for which $\alpha=1.5,2.0$, and 3.0.

We also hypothesize that the divergence of the spectral ratio amplitude at $7 \mathrm{~Hz}$ between numerical predictions and observations is attributed to the presence of a strong impedance contrast at depth such that it does not alter the $7 \mathrm{~Hz}$ mode of soil-column response while enabling the trapping and amplification of incident seismic waves. Given that the site investigation allowed soil properties to be measured only down to a $30 \mathrm{~m}$ depth, we set a hypothetical elastic half-space interface at $100 \mathrm{~m}$ depth (common assumption of the so-called engineering bedrock) and investigate the role of the soilrock impedance contrast by means of the parameter $\alpha_{b}=\left(\rho_{b} V_{S b}\right) /\left(\rho_{3} V_{S 3}\right)$, for which $\alpha_{b}=1.5,2$, and 3 .

Results of the parametric investigation are shown in Figure 16. More specifically, we first illustrate the effects of $\alpha$ for a configuration with $t_{1}=t_{2}=20 \mathrm{~m}, V_{S 1}=500 \mathrm{~m} / \mathrm{s}$, $V_{S 2}=1219 \mathrm{~m} / \mathrm{s}$, and $\alpha_{b}=2$, and show that the presence of a strong impedance contrast within the soil layers below the measured depth indeed increases the amplification magnitude at $7 \mathrm{~Hz}$ compared with the original numerical model and contributes to the lower frequency amplification at the first mode of the soil column above the third layer $(40 \mathrm{~m}$ depth) and the higher frequency amplification at higher modes of the profile $(>10 \mathrm{~Hz}$ ). Next, we illustrate the effects of thickness of soil layer $2, t_{2}$, for a configuration with $t_{1}=20 \mathrm{~m}, \quad V_{S 1}=500 \mathrm{~m} / \mathrm{s}, \quad V_{S 2}=1219 \mathrm{~m} / \mathrm{s}, \quad$ and $\alpha=$ $\alpha_{\mathrm{b}}=2$. This parameter affects both the amplification magnitude in the $6-8 \mathrm{~Hz}$ frequency range and the higher response modes in the frequency range $>10 \mathrm{~Hz}$. Finally, we plot the effects of $\alpha_{\mathrm{b}}$ for a configuration with $t_{1}=t_{2}=20 \mathrm{~m}$, $V_{S 1}=500 \mathrm{~m} / \mathrm{s}, \quad V_{S 2}=1219 \mathrm{~m} / \mathrm{s}$, and $V_{S 3}=2286 \mathrm{~m} / \mathrm{s}$ (or else $\alpha=2$ ), and show that the presence of a soil-bedrock impedance contrast at $100 \mathrm{~m}$ depth further increases the amplification magnitude at $7 \mathrm{~Hz}$ compared with the elastic half-space of the original numerical model.

Results of the simplified configuration with $t_{1}=t_{2}=$ $20 \mathrm{~m}, V_{S 1}=500 \mathrm{~m} / \mathrm{s}, V_{S 2}=1219 \mathrm{~m} / \mathrm{s}$, and $\alpha_{\mathrm{b}}=\alpha=2$ 
(a)

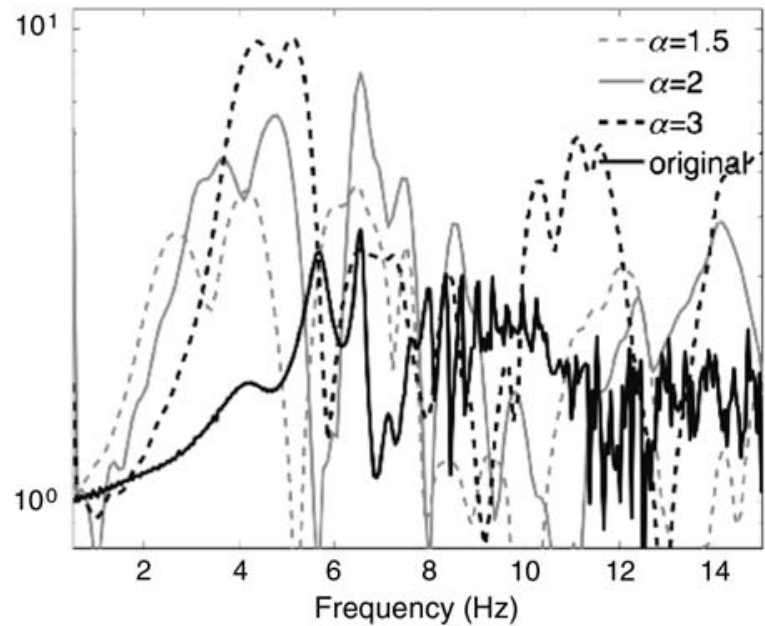

(b)

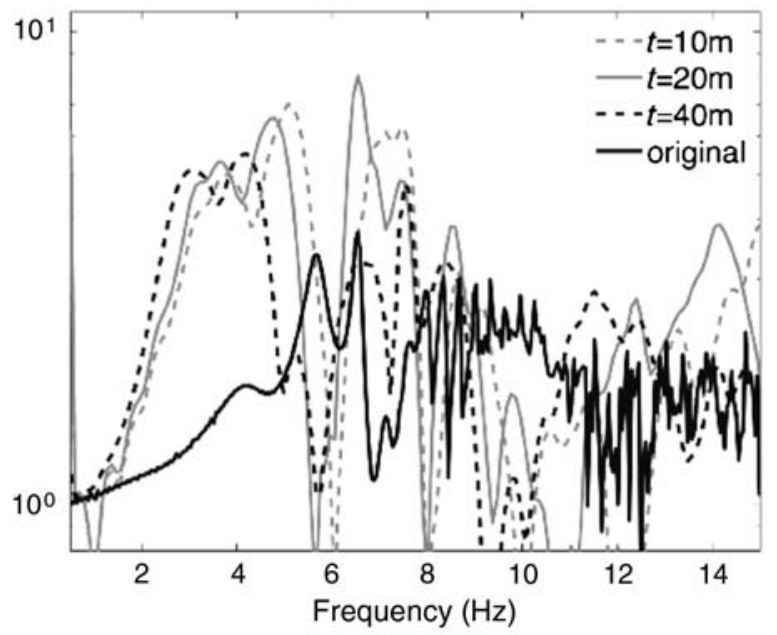

(c)

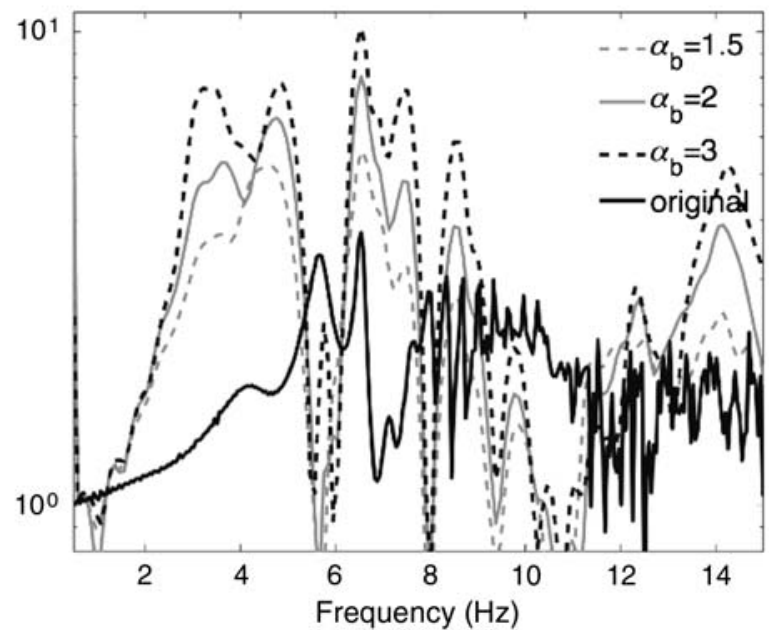

Figure 16. Results of the parametric simulation on the factors affecting the amplification amplitude in the vicinity of $7 \mathrm{~Hz}$ : (a) effects of the impedance contrast between layers 2 and $3(\alpha)$; (b) effects of thickness of soil layer 2, $t_{2}$; and (c) effects of the impedance contrast between soil and underlying bedrock $\left(\alpha_{\mathrm{b}}\right)$ showing that the presence of a soil-bedrock impedance contrast at $100 \mathrm{~m}$ depth further increases the amplification magnitude at $7 \mathrm{~Hz}$ compared to the elastic half-space of the original numerical model.

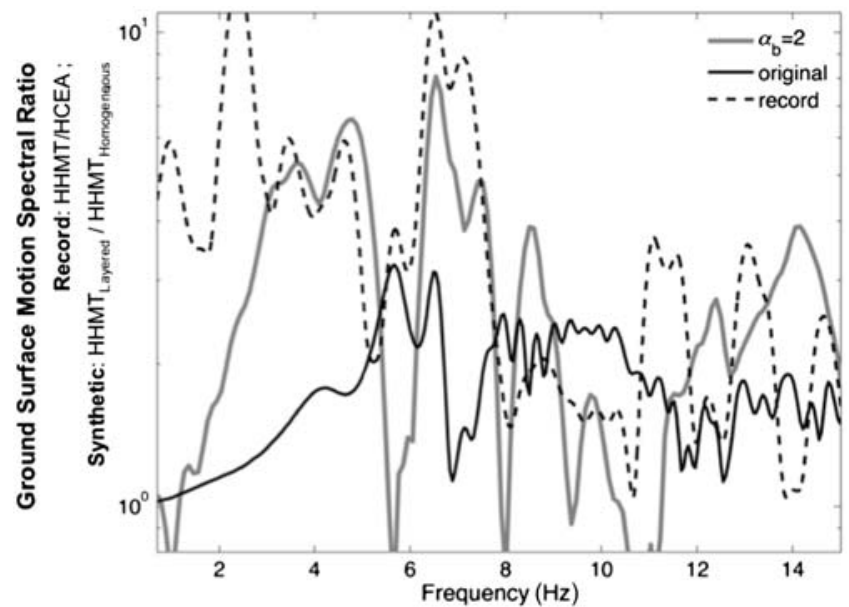

Figure 17. Gray line, results of the simplified configuration with $t_{1}=t_{2}=20 \mathrm{~m}, V_{S 1}=500 \mathrm{~m} / \mathrm{s}, V_{S 2}=1219 \mathrm{~m} / \mathrm{s}$, and $\alpha_{\mathrm{b}}=$ $\alpha=2$ compared with black dashed line, the observed median amplification at HHMT relative to HCEA, and the black continuous line, the numerical results obtained using the original layered configuration. Predicted amplification of the simplified model with added impedance contrast at $100 \mathrm{~m}$ depth are in excellent agreement with the observations both in amplitude and in frequency in the range $3-10 \mathrm{~Hz}$.

are shown in Figure 17, in which the observed median amplification at HHMT relative to HCEA is compared with the numerical results with the original layered configuration and the simplified configuration with added impedance contrast at depth. As can be seen, the results of the parametric model are in excellent agreement with the observations in both amplitude and frequency in the range 3-10 Hz. Our parametric study suggests that the amplitude discrepancy between predictions and observations may well be attributed in part to incomplete information of the local soil conditions at HHMT (30 $\mathrm{m}$ deep profile available), and our hypothesis of deeper soil interfaces with strong impedance contrast results in ground-motion amplification that quantitatively agrees with the recorded spectral ratios at Hotel Montana.

\section{Conclusions}

Following up on the work by Hough et al. (2011), we conducted site-specific analyses of coupled topography-soil amplification effects at the hilltop ridge of Hotel Montana. Our simulations revealed that the observed ground-motion amplification at station HHMT relative to the reference station HCEA on competent rock is potentially the result of topography-modified site response rather than topographic amplification alone. Observations and site-specific simulations were found to be in good qualitative agreement, yet quantitatively, the predicted amplification in the frequency range (6-8) $\mathrm{Hz}$ was found to underestimate the field recordings by a factor of three. We next investigated the parameters controlling the amplitude and frequency content of the coupled topography-soil observed amplification, and identified the thickness of sediments, the soil layer stiffness, and 
impedance contrast as the dominant parameters. The soil to elastic half-space impedance was shown to affect the amplitude of surface ground motion in the resonant frequency of the surface sediments, and for a contrast equal to $\alpha=2$, the predicted ground-motion amplification quantitatively compares with the observations in frequency and amplitude as shown in Figure 17. Also, the thickness of the sedimentary layer and the impedance contrast below $30 \mathrm{~m}$ were shown to contribute to the fairly systematic secondary amplification at lower frequencies, namely 3-4 Hz.

We therefore conclude that the ground-motion observations at Hotel Montana and the damage concentration at the hilltop was governed by soil amplification effects, manifesting in the frequency range of 1D soil response $(7 \mathrm{~Hz})$ and modified due to scattering and refraction of the seismic waves by the irregular ground surface. Soil characterization was available only at the top $30 \mathrm{~m}$ of the HHMT site, and most likely, the presence of a deeper soil layers of higher stiffness further aggravated the amplification of seismic waves in the near surface. Future site investigation studies using in situ or surface-wave exploration techniques with resolution below $30 \mathrm{~m}$ would nonetheless be needed to verify our hypothesis.

Our paper shows that coupling between topography and soil-amplification effects gives rise to complex wavepropagation patterns in excess of the superposition of the two phenomena, and a more detailed parametric investigation of the phenomena for generic topographic features and soil profiles is currently in progress. Among other factors, we are investigating coupled soil-topography effects during strong ground motion, in which nonlinear effects are most likely to occur, and the coupling effects are anticipated to be yet more pronounced: altering of the direction of incident waves by nonflat ground conditions lead to nonuniform stiffness reduction due to nonlinear effects, which in turn further aggravates the scattering and diffraction of body waves due to the presence of reduced stiffness soil patches within the medium, in addition to the surface geometry irregularities. The overarching goal of our ongoing parametric studies, complemented by well-documented case studies like the one presented here, is the compilation of our results into simplified space- and frequency-dependent factors that describe seismic motion amplification in excess of soil response in the vicinity of irregular ground-surface features, and can be integrated in seismic code provisions, attenuation relations, microzonation studies, and seismic-hazard maps to account for topographic amplification in hazard assessment, mitigation, and engineering-design practices.

\section{Data and Resources}

Aftershock recordings used to estimate the empirical amplification factors in this study were obtained via personal communication with S. Hough (October 2010) and A. Yong (September 2010). Recordings are currently available through the Incorporated Research Institutions for Seismology Data Management Center (IRIS DMC) http://www.iris .edu/dms/dmc (last accessed August 2012). Velocity profiles are described in Cox et al. (2011). Simulation results and input files are available on request from the authors.

\section{Acknowledgments}

This material is based upon work supported by the National Science Foundation under Grant Number CMMI-0936543 with title "NEESR-CR: Topographic Effects in Strong Ground Motion: From Physical and Numerical Modeling to Design" and Grant Number CMMI-1030728 with title "Topographic Amplification of Seismic Motion: Observations and Simulations in 3D". Any opinions, findings, and conclusions or recommendations expressed in this material are those of the author(s) and do not necessarily reflect the views of the National Science Foundation. The authors would also like to thank Susan Hough and Alan Yong from the U. S. Geological Survey Pasadena Office, Brady Cox from the University of Arkansas, and Jamison H. Steidl from the Institute of Crustal Studies at the University of California Santa Barbara for their help in providing the digital elevation, strong-motion aftershock recordings, SASW soil profile data, and their insightful comments on our research findings presented here. The constructive reviews by F. Sanchez-Sesma, M. Chapman, and an anonymous reviewer are hereby also acknowledged.

\section{References}

Ashford, S. A., N. Sitar, J. Lysmer, and N. Deng (1997). Topographic effects on the seismic response of steep slopes, Bull. Seismol. Soc. Am. 87, no. 3, 701-709.

Assimaki, D. (2004). Topography effects in the 1999 Athens earthquake: Engineering issues in seismology, Ph.D. Dissertation, Department of Civil and Environmental Engineering, Massachusetts Institute of Technology.

Assimaki, D., G. Gazetas, and E. Kausel (2005). Effects of local soil conditions on the topographic aggravation of seismic motion: Parametric investigation and recorded field evidence from the 1999 Athens earthquake, Bull. Seismol. Soc. Am. 95, no. 3, 1059-1089.

Assimaki, D., E. Kausel, and G. Gazetas (2005). Soil-dependent topographic effects: A case study from the 1999 Athens earthquake, Earthq. Spectra 21, no. 4, 929-966.

Association Francaise de Génie ParaSismique (1995). The 1995 French Seismic Code. Guidelines for Seismic Microzonation Studies.

Bard, P.-Y. (1982). Diffracted waves and displacement field over twodimensional elevated topographies, Geophys. J. Roy. Astron. Soc. 72, 731-760.

Bard, P.-Y. (1999). Local effects on strong ground motion: Physical basis and estimation methods in view of microzoning studies, in Proc. of the Advanced Study Course on Seismotectonic and Microzonation Techniques in Earthquake Engineering, Kefallinia, Greece, Vol. 4, 127-218.

Bard, P.-Y., and B. E. Tucker (1985). Underground and ridge site effects: A comparison of observation and theory, Bull. Seismol. Soc. Am. 75, no. 4, 905-922.

Boore, D. M. (1972). A note on the effect of simple topography on seismic SH waves, Bull. Seismol. Soc. Am. 62, no. 1, 275-284.

Bouchon, M. (1973). Effect of topography on surface motion, Bull. Seismol. Soc. Am. 63, no. 3, 615-632.

Bouchon, M., and J. Barker (1996). Seismic response of a hill: The example of Tarzana, California, Bull. Seismol. Soc. Am. 86, no. 1A, 66-72.

Bouchon, M., C. A. Schultz, and M. N. Toksöz (1996). Effect of threedimensional topography on seismic motion, J. Geophys. Res. 101, no. B3, 5835-5846.

Cox, B. R., J. Bachhuber, E. Rathje, C. M. Wood, R. Dulberg, A. Kottke, R. A. Green, and S. M. Olson (2011). Shear wave velocity- and geology-based microzonation of Port-au-Prince, Haiti, Earthq. Spectra 27, no. S1, S67-S92.

European Committee for Standardization (2000). EC8 Design Provisions for Earthquake Resistance of Structures, Part 1-1: General 
Rules-Seismic Actions and General Requirements for Structures: prFN 1998-5, Brussels.

Everhard, M. O., S. Baldridge, J. Marshall, W. Mooney, and G. J. Rix (2010). The $M_{\mathrm{w}} 7.0$ Haiti earthquake of January 12, 2010, USGS/ EERI advance reconnaissance team report, U.S. Geol. Surv. Open-File Rept. 2010-1048, USGS/EERI.

Faccioli, E. (1991). Seismic amplification in the presence of geological and topographic irregularities, in Proc. of the 2nd International Conference on Recent Advances in Geotechnical Earthquake Engineering and Soil Dynamics, St. Louis, Missouri, Vol. 2, 1779-1797.

Finn, W. (1991). Geotechnical engineering aspects of seismic microzonation, in Proc. of 4th International Conference on Seismic Zonation, EERI, Stanford, California, Vol. 1, 199-250.

Geli, L., P.-Y. Bard, and B. Jullien (1988). The effect of topography on earthquake ground motion: A review and new results, Bull. Seismol. Soc. Am. 78, no. 1, 42-63.

Geoengineering Extreme Events Reconnaissance (GEER) (2010). Geotechnical engineering reconnaissance of the 2010 Haiti earthquake, Reconnaissance report

Graizer, V. (2009). Low-velocity zone and topography as a source of site amplification effect on Tarzana hill, California, Soil Dynam. Earthq. Eng. 29, no. 2, 324-332.

Hough, S. E., J. R. Altidor, D. Anglade, D. Given, M. G. Janvier, J. Z. Maharrey, M. Meremonte, B. S.-L. Mildor, C. Prepetit, and A. Yong (2011). Localized damage cauded by topographic amplification during the $2010 \mathrm{~m} 7.0$ Haiti earthquake, Nature Geosci. 3, 778-782.

Lee, S.-J., D. Komatitsch, B.-S. Huang, and J. Tromp (2009). Effects of topography on seismic-wave propagation: An example from northern Taiwan? Bull. Seismol. Soc. Am. 99, no. 1, 314-325.

Maufroy, E., V. M. Cruz-Atienza, and S. Gaffeta (2012). A robust method for assessing 3-D topographic site effects: A case study at the LSBB Underground Laboratory, France, Earthq. Spectra 28, no. 3, 1097-1115.

Nagashima, F., H. Kawase, S. Matsushima, F. J. Sanchez-Sesma, T. Hayakawa, T. Satoh, and M. Oshima (2012). Application of the $\mathrm{H} / \mathrm{V}$ spectral ratios for earthquake ground motions and microtremors at K-NET sites in Tohoku region, Japan to delineate soil nonlinearity during the 2011 Off the Pacific Coast of Tohoku earthquake, in Proc. of the International Symposium on Engineering Lessons Learned from the 2011 Great East Japan Earthquake, Tokyo, Japan.
Nechtschein, S., P.-Y. Bard, J.-C. Gariel, J.-P. Mèneroud, P. Dervin, M. Cushing, B. Gaubert, S. Vidal, and A.-M. Duval (1995). A topographic effect study in the Nice region, in Proc. of the Fifth International Conference on Seismic Zonation, Ouest Édition, Nice, France, Vol. 2, 1067-1074.

Paolucci, R., E. Faccioli, and F. Maggio (1999). 3D response analysis of an instrumented hill at Matsuzaki, Japan, by a spectral method, J. Seismol. 3, 191-209.

Prévost, J.-H. (1995). Dynaflow: A nonlinear transient finite element analysis program, Princeton University.

Sanchez-Sesma, F. J. (1983). Diffraction of elastic waves by threedimensional surface irregularities, Bull. Seismol. Soc. Am. 73, no. 6, $1621-1636$

Sanchez-Sesma, F. J. (1990). Elementary solutions for response of a wedge-shaped medium to incident SH and SV waves, Bull. Seismol. Soc. Am. 80, no. 3, 737-742.

Sanchez-Sesma, F. J., I. Herrera, and J. Aviles (1982). A boundary method for elastic wave diffraction: Application to scattering of SH waves by surface irregularities, Bull. Seismol. Soc. Am. 72, no. 2, 473-490.

Smith, W. D. (1975). The application of finite element analysis to body wave propagation problems, Geophys. J. Roy. Astron. Soc. 42, no. 2, 747-768.

Steidl, J. H., A. G. Tumarkin., and R. J. Archuleta (1996). What is a reference site? Bull. Seismol. Soc. Am. 86, no. 6, 1733-1748.

Tucker, B., J. King, D. Hatzfeld, and I. Nersesov (1984). Observations of hard rock site effects, Bull. Seismol. Soc. Am. 74, no. 1, 121-136.

Zhenpeng, L., Y. Baipo, and Y. Yifan (1980). Effect of three-dimensional topography on earthquake ground motion, in Proc. of the 7th World Conference on Earthquake Engineering, Vol. 2, 161-168.

Department of Civil and Environmental Engineering

790 Atlantic Drive NW

Atlanta, Georgia 30332-0355

dominic@gatech.edu

s.jeong@gatech.edu 